\title{
Primary Subcutaneous Hydatid Cyst of the Face: A Rare Entity with Emphasis on Radiological Evaluation
}

\author{
Neha Nischal, ${ }^{1,}$ Amit Kumar Verma, ${ }^{1}$ and Deepak Bhangale ${ }^{2}$ \\ ${ }^{1}$ Department of Radiology, GB Pant Hospital, New Delhi, India \\ ${ }^{2}$ Department of Neurosciences, Medanta Hospital, Gurgaon, India \\ "Corresponding author: Neha Nischal, Department of Radiology, GB Pant Hospital, New Delhi, India. E-mail: neha.nischal@gmail.com
}

Received 2017 February 21; Accepted 2017 May 23.

\begin{abstract}
Despite being an extremely common disease worldwide, especially in the temperate areas, hydatid disease continues to startle by varying presentations. The current study presented a case of primary hydatid in the subcutaneous region of face of a young patient accurately diagnosed preoperatively by the characteristic of imaging findings on ultrasonography (USG) and comouted tomography (CT) and confirmed on surgery. Although it was a rare site of presentation, the radiological features were essentially the same as elsewhere in the body and could help to make correct decision to manage the patient.
\end{abstract}

Keywords: Hydatid Cyst, Subcutaneous, Radiological Features

\section{Introduction}

Primary subcutaneous hydatid cyst is a rare ocurrence comprised only about $1 \%$ to $2 \%(1,2)$ all hydatide cases. To the best of authors' knowledge, only one case of primary hydatid of the face is published from India, and the current case is the 2nd (3). The current study highlighted the importance of radiological examination, which can be quite specific in certain cases and can help in preoperative planning.

\section{Case Presentation}

The case was an 8-year-old male from a rural area presented with a slow-growing painless swelling over the left zygomatico-temporal region since 2 years (Figure 1 ). The mother gave a remote and only history of minor head trauma. On examination, the swelling was firm and nontender with no signs of inflammation. Its movement was restricted in all directions and measured about $8 \times 5 \mathrm{~cm}$. The child was sent to the radiology department for further evaluation. On ultrasonography (USG), the mass was found to be unilocular cystic lesion with thick internal septations, which showed no significant vascularity on colour doppler (Figure 2A and 2B). Ultrasound examination of the abdomen was unremarkable. A computed tomography (CT) scan was planned to further characterise the lesion. It showed a well-defined fluid attenuating lesion in the left zygomatico-temporal region measuring about $7 \times 5 \mathrm{~cm}$. A thick undulating membrane was observed within the lesion, clinching the diagnosis of hydatid cyst. The underlying zygomatic arch showed smooth expansion with thinning without any cortical breach (Figure 3A and 3B). A chest radiograph was then taken, which did not reveal any abnormality. The patient was negative for hydatid serology.

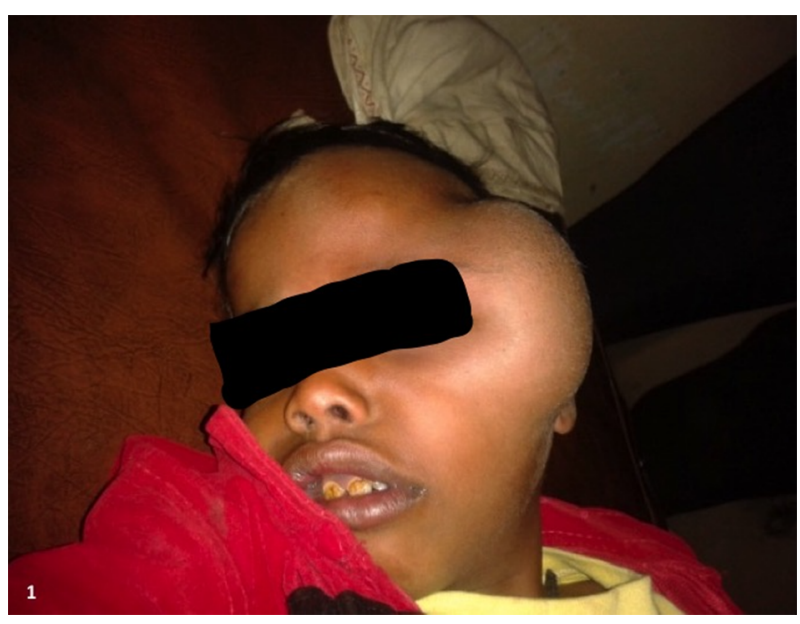

Figure 1. Clinical Photograph of the Patient- a Large Swelling Over Left ZygomaticoTemporal Region

The child was operated under general anaesthesia with 

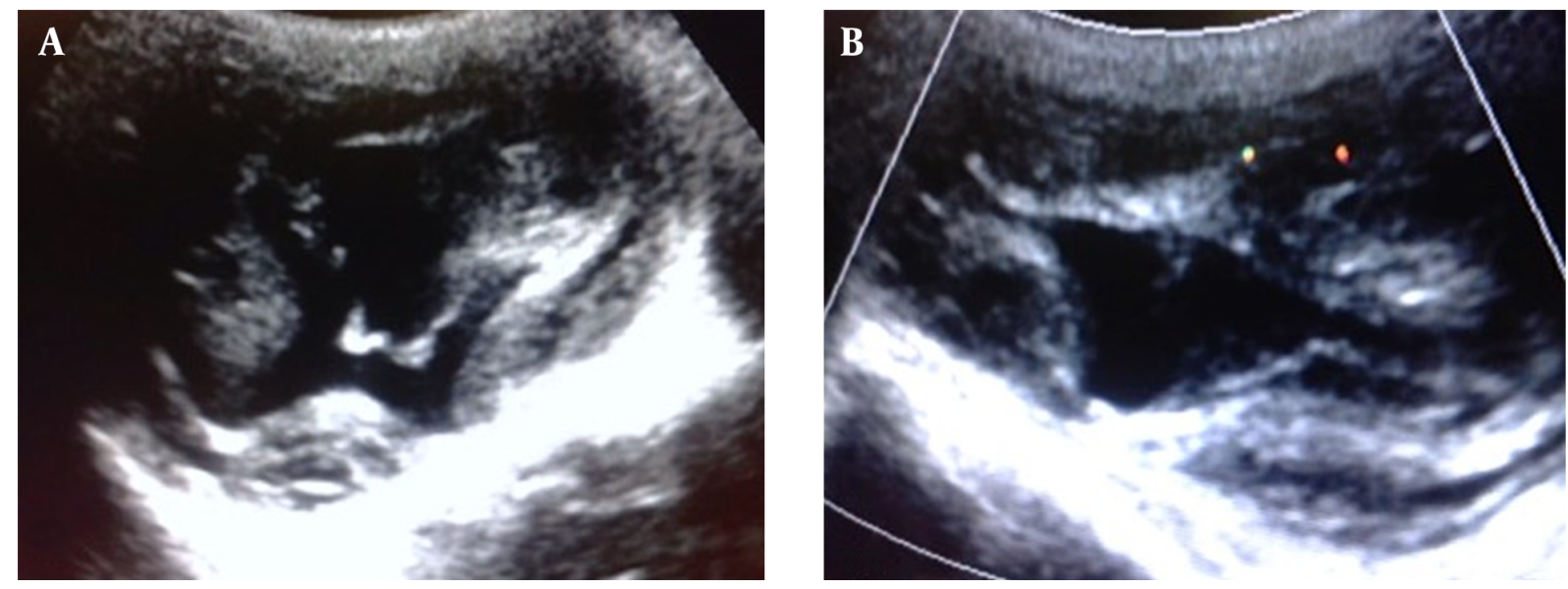

Figure 2. A, Sonographic image of the lesion showing thick-walled cystic lesion with thick echogenic internal membranes; B, The color Doppler image did not reveal any significant vascularity.
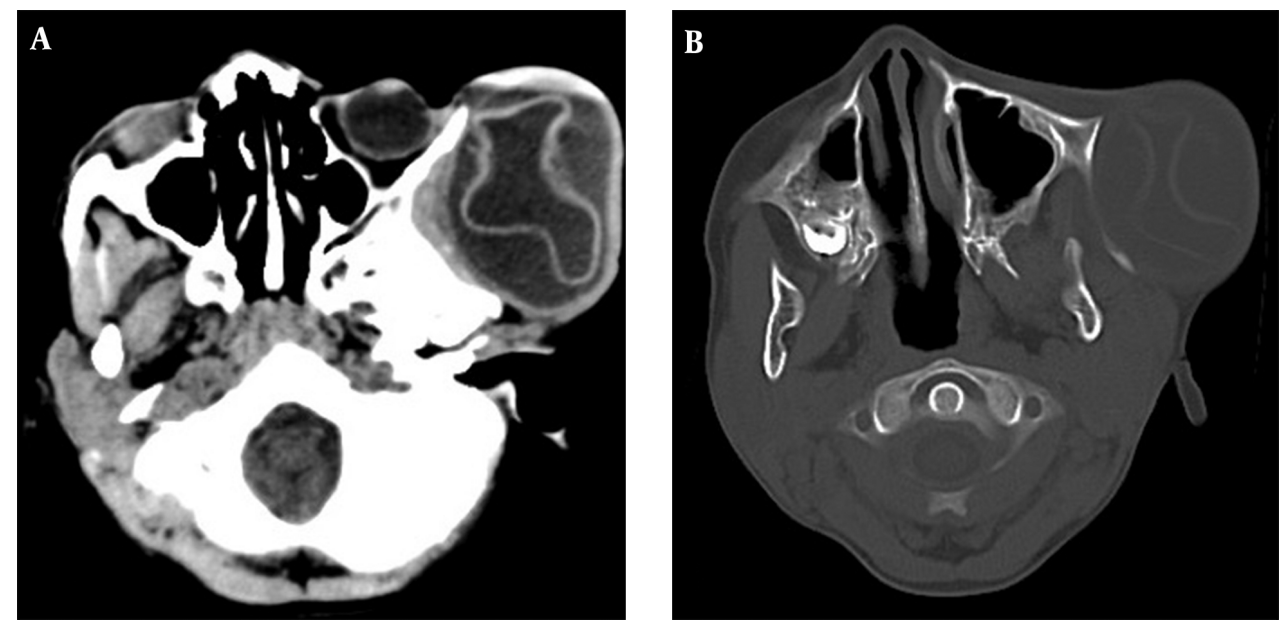

Figure 3. A and B, Axial non-contrast CT images in soft tissue and bone window showing a large thick walled cystic lesion with undulating thick hyperdense membrane over the left zygomatico-temporal region causing scalloping of underlying bone.

total excision of the cyst with intact membranes. The membranes appeared pearly white and clear brownish fluid was aspirated from the cyst (Figure 4). The child was discharged on albendazole $15 \mathrm{mg} / \mathrm{kg}$ in 2 doses for 3 months. A1 year follow-up revealed no recurrence or presence of hydatid disease in any other organ.

\section{Discussion}

Hydatid cyst is caused by the larval form of Echinococcus granulosus and is endemic in many tropical countries including India. The most common sites of affliction are liver followed by lungs. Ocurrence of primary subcutaneous hydatid disease is an extremely infrequent occur- rence (1) and involvement of head and neck appears to be one of the rarest primary sites (2). It is why a clinical diagnosis in such cases is not apprehended and the radiologist is mostly the one to give a correct diagnosis. Hydatid serology may also be negative in chronic cases $(1,4)$; as observed in the current case. Primary disease of the face appears to be more common in the younger population, as observed in the current case $(5,6)$.

Radiological evaluation is important to characterise the lesion and rule out involvement of other organs. Imaging appears to be more sensitive than serodiagnosis in such cases (2). Ultrasound is the first investigation to evaluate any soft tissue lesion. On USG, hydatid cyst has a variable appearance and is categorised into 5 major types ac- 


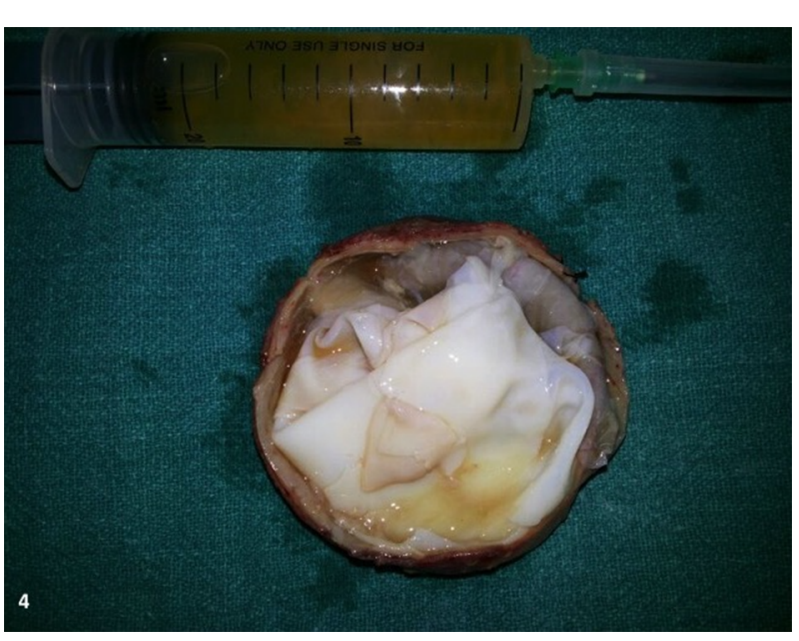

Figure 4. Intraoperative Specimen with the Glistening Pearly White Capsule and Brownish Fluid

cording to the World Health Orgnization (WHO) classification (7).

CL - Unilocular anechoic cystic lesion without any internal echoes and septations.

CE 1 - Uniformly anechoic cyst with fine echoes representing hydatid sand.

CE 2-Cyst with multiple septations giving it multivesicular appearance or rosette appearance or honey comb appearance with unilocular mother cyst, diagnostic of hydatid cyst.

CE 3 - Unilocular cyst with daughter cysts with detached laminated membranes appearing as water lily sign.

CE 4 - Mixed hypo and hyperechoic contents with absent daughter cysts, indicating the degenerative nature of the cyst.

CE 5 - Arch like thick partially or completely calcified wall- inactive and infertile stage.

Further evaluation with CT/MRI is usually conducted to assess the extent and multiplicity of the lesion apart from characterization, for which magnetic resonance imaging (MRI) is usually preferred over CT. A hypointense rim on T2-weighted MR images is proposed as a typical sign of hydatid disease, but is non-specific (8). However, CT may be preferred due to the prohibitive cost of MRI and to evaluate the status of underlying bones.

Treatment is mostly surgical and involves complete excision of the cyst wherever possible (5). Cysts in subcutaneous location appear to be at a low risk of allergy in case of accidental spillage and recurrence is quite rare (9). Medical treatment with albendazole is mostly given postoperatively for 2 to 4 months.

\section{Acknowledgments}

None declared.

\section{Footnote}

Financial Disclosure: Authors declared no financial disclosure regarding this manuscript.

\section{References}

1. Chevalier X, Rhamouni A, Bretagne S, Martigny J, Larget-Piet B. Hydatid cyst of the subcutaneous tissue without other involvement: MR imaging features. AJR Am J Roentgenol. 1994;163(3):645-6. doi: 10.2214/ajr.163.3.8079861. [PubMed: 8079861].

2. Dirican A, Unal B, Kayaalp C, Kirimlioglu V. Subcutaneous hydatid cysts occurring in the palm and the thigh: two case reports. J Med Case Rep. 2008;2:273. doi: 10.1186/1752-1947-2-273. [PubMed: 18700983].

3. Bansal C, Lal N, Jain RC, Srivastava AN, Fatima U. Primary hydatid cyst in the soft tissue of the face: an exceptional occurrence. Indian J Dermatol. 2011;56(6):768-70. doi: 10.4103/0019-5154.91852. [PubMed: 22345794].

4. Ay S, Okus A, Demirgul R, Eryilmaz MA, Atay A. Primary subcutaneous cyst hydatid: presentation of two cases. Turkiye Parazitol Derg. 2013;37(3):219-21. doi:10.5152/tpd.2013.49. [PubMed: 24192628].

5. Vecchio R, Marchese S, Ferla F, Spataro L, Intagliata E. Solitary subcutaneous hydatid cyst: review of the literature and report of a new case in the deltoid region. Parasitol Int. 2013;62(6):487-93. doi: 10.1016/j.parint.2013.06.013. [PubMed: 23838268].

6. Belcadhi M, Kermani W, Mani R, Zeglaoui I, Ben Ali M, Abdelkefi $\mathrm{M}$, et al. [Cervico-facial hydatidosis. Report of 17 cases]. Tunis Med. 2011;89(4):336-41. [PubMed: 21484681].

7. Giorgio A, Di Sarno A, de Stefano G, Liorre G, Farella N, Scognamiglio $\mathrm{U}$, et al. Sonography and clinical outcome of viable hydatid liver cysts treated with double percutaneous aspiration and ethanol injection as first-line therapy: efficacy and long-term follow-up. AJR Am J Roentgenol. 2009;193(3):W186-92. doi: 10.2214/AJR.08.1518. [PubMed: 19696257].

8. Polat P, Kantarci M, Alper F, Suma S, Koruyucu MB, Okur A. Hydatid disease from head to toe. Radiographics. 2003;23(2):475-94. doi: 10.1148/rg.232025704. [PubMed:12640161] quiz 536-7.

9. Singh S, Khichy S, Singh M, Gill JS. Recurrent solitary hydatid cyst of the subcutaneous tissue. Indian JSurg. 2009;71(3):162-4. doi:10.1007/s12262009-0044-1. [PubMed: 23133143]. 